\title{
Staffing policy in aged care must look beyond the numbers
}

\author{
Sarah Wise (iD) LLB, MSc, PhD, Senior Research Fellow
}

Centre for Health Economic Research and Evaluation, UTS Business School, University of Technology

Sydney, PO Box 123, Broadway, NSW 2007, Australia. Email: sarah.wise@uts.edu.au

\begin{abstract}
The COVID-19 pandemic has highlighted an aged care system struggling to meet the needs of vulnerable Australians. Staffing levels and skill mix in aged care have declined, whereas the health and social needs of an older and more clinically complex population have risen. Increasing staff and improving personal care workers' skills and education are essential steps to quality aged care in Australia, but it will not be possible without funding models that foster secure employment, development opportunities and long-term career pathways.
\end{abstract}

Keywords: aged care, health funding and financing, health policy, workforce.

Received 30 October 2020, accepted 30 October 2020, published online 1 December 2020

The COVID-19 pandemic has highlighted an aged care system struggling to meet the needs of vulnerable Australians. Although rates of infections and deaths in residential facilities have been relatively low by international standards, when outbreaks did occur the sector was not prepared. Even where sufficient personal protective equipment was available, the unregulated personal care workers (PCWs) trained for jobs in aged care did not know how to use it. ${ }^{1}$ Personal care workers' lack of basic skills in infection control is consistent with the mounting body of evidence garnered by the Royal Commission into Aged Care Quality and Safety that staffing levels and skill mix (i.e. the proportion of care provided by professional nurses rather than PCWs) have declined in absolute terms, as well as relative to the rising health and social needs of an older and more clinically complex population. More than half of Australian aged care residents (57.6\%) are living in facilities with 'unacceptable' staffing, ${ }^{2}$ and a survey of 2018-19 home care package expenditure found that even at the highest level of need, only $2 \%$ of allotted funds were spent on professional nursing care (nurse practitioners, registered nurses and enrolled nurses). ${ }^{3}$

The staffing situation in aged care is in stark contrast to that in Australian public hospitals, which enjoy some of the highest levels of professional nurse staffing in the world due to industrial agreements in most states. Mandated minimum nurse staffing standards (for numbers and skill mix) are often deeply unpopular with governments, and problematic for managers when implemented inflexibly, ${ }^{4}$ but are infinitely preferable to the voluntary approach that gradually took hold in aged care. When the Aged Care Funding Instrument (ACFI) was introduced for residential care in 2008, a requirement for providers to ring fence and account for staff funding was removed, creating a financial incentive to deskill the workforce by replacing professional nurses with cheaper PCWs. This problem was flagged by the Productivity Commission in 2011,5 yet in 2014 the federal government lifted the last staffing safeguard: that residential facilities must have a registered nurse (RN) on duty $24 \mathrm{~h}$ per day. Moreover, funding levels set by ACFI and the Home Care Package program were never based on an analysis of the staffing required to meet older people's needs. ACFI is to be replaced with an evidence-based finding model that matches staffing with an assessment of frailty, mobility, motor function, cognition, behaviour, and technical nursing needs. ${ }^{6}$ If the ring fencing and accounting requirements removed in 2008 are reintroduced, this will go some way to improving staffing in residential facilities. Given the small proportion of package funding spent on professional nursing care, a similar model is desperately needed in home care. Increasing the staffing numbers overall and improving skill mix is an essential step towards an aged care sector Australia can be proud of, but it is not enough.

Most PCWs have a (non-mandatory) Certificate $\mathrm{III}^{7}{ }^{7}$ but the quality of training is highly variable and does not incorporate the complex skills involved to effectively perform such intimate roles. Providing safe, quality personal care for frail, elderly people involves not only the tasks themselves, but also an assessment of well-being, identifying any physical and mental deterioration, and escalating concerns to a professional nurse. The lack of effective surveillance of older people's health and emotional status contributes to poor outcomes when those needs are not addressed in a timely manner, leading to avoidable hospital admissions or early entry to residential care. Similar concerns have been raised about the training and skills for nursing assistants in hospitals, but they must work under the supervision of an RN. Although these supervision arrangements can be problematic in practice, they do provide an escalation structure and opportunity to develop assistants' skills. ${ }^{8}$ There are no such supervisory requirements for PCWs in aged care, and limited opportunities for on-the-job learning. The limited number of RNs working in residential facilities means that the RNs 
are often too overloaded with administrative tasks to provide meaningful oversight. ${ }^{5}$ In home care, PCWs work alone and many providers do not employ RNs at all. The Royal Commission has proposed that PCWs in home care should be qualified to Certificate IV level and registered like other health professionals, reforms both residential facilities and hospitals would benefit from. Increasing the number of professional nurses providing direct care and effective supervisory structures for PCWs are essential to respond to people's changing needs outside of hospital, particularly at the end of life, where Australia has a very poor record. ${ }^{9}$ The increased use of nurse practitioners is a crucial component for keeping older people out of hospital, but current restrictions on their access to the Medicare Benefit Schedule have to be removed. ${ }^{10}$

Seamless care provided at the appropriate level, supported by effective supervision and timely communication also relies on continuity in the team providing care. ${ }^{8}$ However, employment conditions marked by high levels of casualisation for PCWs and subcontracting arrangements for professional nurses do not support this. Lack of continuity in caregivers is, in itself, highly problematic for a vulnerable, often cognitively impaired population. There is also significant vulnerability in the workforce, with those on a temporary visa more likely to be casual and underemployed. ${ }^{11}$ An unstable, contingent workforce is an unintended consequence of policy that has tied funding to individuals rather than organisations. It has produced a volatility and inflexibility in providers' finances that makes it impossible to offer good-quality jobs. Poor job quality, compounded by relatively low pay and a poor public image, means the sector cannot attract or retain the professional and care staff needed to meet ever-rising demand.

The Royal Commission has exposed the successive failure of aged care policies that have consistently downplayed the rising clinical and behavioural needs of older people, and is advocating strongly for increases in staff numbers and improvements in skill mix. In such a deeply human business, quality aged care will not be possible without improving job quality, supported by funding models that foster secure employment, development opportunities and long-term career pathways.

\section{Competing interests}

There are no competing interests to declare.

\section{Acknowledgements}

The authors thank Christine Duffield for helpful comments on a draft of this paper. The views expressed in this Perspective are the author's own. There are no funding sources to declare.

\section{References}

1 Royal Commission into Aged Care Quality and Safety. Aged care and COVID-19: a special report. 2020. Available at: https://agedcare.royalcommission.gov.au/sites/default/files/2020-10/aged-care-and-covid19-a-special-report.pdf [verified 11 November 2020].

2 Eagar K, Westera A, Snoek M, Kobel C, Loggie C, Gordon R. How Australian residential aged care staffing levels compare with international and national benchmarks. Canberra: Centre for Health Service Development, Australian Health Services Research Institute, University of Wollongong; 2019.

3 StewartBrown. Home care provider survey. Analysis of data collected, April 2020. Canberra: Australian Government Department of Health; 2020. Available at: https://www.health.gov.au/resources/publications/ home-care-provider-survey-analysis-of-data-collected [verified 16 November 2020].

4 Duffield C, Roche MA, Wise S, Debono D. Harnessing ward-level administrative data and expert knowledge to improve staffing decisions: a multi-method case study. $J$ Adv Nurs 2020; 76: 287-96. doi:10.1111/ jan. 14207

5 Productivity Commission. Caring for older Australians. Canberra: Productivity Commission; 2011.

6 Eagar K, Gordon R, Snoek MF, Loggie C, Westera A, Samsa PD, Kobel C. The Australian National Aged Care Classification (AN-ACC): a new casemix classification for residential aged care. Med J Aust 2020; 213 : 359-63. doi:10.5694/mja2.50703

7 Mavromaras K, Knight G, Isherwood L, Crettenden A, Flavel J, Karmel T, Moskos M, Smith L, Walton H, Wei Z. The aged care workforce, 2016. Canberra: Australian Government Department of Health; 2017. Available at: https://www.gen-agedcaredata.gov.au/www_aihwgen/ media/Workforce/The-Aged-Care-Workforce-2016.pdf verified 16 November 2020].

8 Duffield C, Twigg D, Roche M, Williams A, Wise S. Uncovering the disconnect between nursing workforce policy intentions, implementation, and outcomes: lessons learned from the addition of a nursing assistant role. Policy Polit Nurs Pract 2019; 20: 228-38. doi:10.1177/ 1527154419877571

9 Broad JB, Gott M, Kim H, Chen H, Connolly MJ. Where do people die? An international comparison of the percentage of deaths occurring in hospital and residential care settings in 45 populations, using published and available statistics. Int $J$ Public Health 2013; 58: 257-67. doi: 10.1007/s00038-012-0394-5

10 Wise S, Duffield C, Fry M, Roche M. Workforce flexibility - in defence of professional healthcare work. J Health Organ Manag 2017; 31: $503-$ 16. doi:10.1108/JHOM-01-2017-0009

11 Charlesworth S, Isherwood L. Migrant aged-care workers in Australia: do they have poorer-quality jobs than their locally born counterparts? Ageing Soc 2020. doi:10.1017/S0144686X20000525 